\title{
Learner's Perceptions of Assessment and Testing in EFL Classrooms in Albania
}

\author{
Dr. Laureta Vavla \\ Aleksander Xhuvani University, Faculty of Human Sciences \\ Department of English and German Languages \\ Email: lauretavavla@yahoo.com \\ Dr. Rregjina Gokaj \\ University "Aleksandër Moisiu" Durrës \\ Faculty of Education, Foreign Languages Department \\ Email: rregjinagokaj@gmail.com
}

Doi:10.5901/mjss.2013.v4n11p509

\section{Abstract}

This paper presents the results of a study concerning learner perceptions of assessment and testing, the effects they have on them, the pros and cons of using tests and assessment in teaching EFL. Responding to both closed questions and openresponse written questions as well as to individual interviews, learners at seven Albanian 9-year schools believed that assessment was an activity done by the teacher to the students and they could not and did not play any role in it. Although general assessments and examinations assess only a moment of the learning process and can be demotivating, they considered them as necessary and mandatory. The students expressed that assessment was the teacher's task and that they did not have a say in it. They were able to critically think about tests and assessment and gave their respective recommendations.

Keywords: assessment, testing, learning processes, learner autonomy

\section{Introduction and Research Background}

Assessment is an integral part of teaching and learning. (Hamp-Lyons \& Condon, 2000) Every teacher knows this well. But what do their students think about assessment? What are their views regarding the advantages and disadvantages of using assessment techniques in EFL classrooms? Recently, in Albania, assessment has become a buzz word and teachers are on their first steps of using alternative means of assessment rather than the traditional testing methods. The current pilot study examines students' perceptions of assessment in an EFL setting, at the secondary level education in Albania. For this pilot study, questionnaires were collected from 80 students of the sixth grade, in seven separate 9-year schools in Elbasan, Albania.

\section{What Exactly is "Assessment" and How Does it Differ from "Testing"?}

The term assessment has been widely used in education circles around the world as well as in Albania, but it is often found that the terms "testing" and "assessment" are used synonymously, which is not right. "A test is a method of measuring a person's ability or knowledge in a given domain, with an emphasis on the concepts of method and measuring. Tests are instruments that are (usually) carefully designed and that have identifiable scoring rubrics. Tests are prepared administrative procedures that occupy identifiable time periods in a curriculum when learners muster all their faculties to offer peak performance, knowing that their responses are being measured and evaluated" (Brown, 2007). On the other hand, assessment is an ongoing process which lies in a much wider domain. Every time a student answers a question, gives a comment, or tries to pronounce a new word, phrase or concept the teacher unconsciously makes an assessment of the student's performance. According to Brown, a good teacher never ceases to assess students, whether those assessments are incidental or intentional.

After this analysis, it becomes obvious that tests are only subsets of assessment, but they certainly are not the only forms of student assessment. Tests are used by teachers as very useful and effective tools to measure students' knowledge, but they constitute only a part of many other procedures and tools that teachers can use to assess their 
students. Therefore, throughout the following paper, the use of the term assessment will include testing in itself as an assessment tool while the latter will be considered more comprehensive and more global than testing.

\section{Research questions and methodology}

Three research questions (RQ's) were devised for this pilot study:

- What effects does assessment have on the students?

- When, what and how are students assessed and tested?

- Are students given the possibility to self - assess or peer - assess?

The questionnaire consists of two sections, where the first section seeks to collect general bio data on students more specifically on school name, grade, and their age group. While the second section seeks to estimate the impact assessment has on them, the frequency of its performance by teachers, types of activities included, where they focus more, the most common mistakes students make when being tested and assessed, etc.

Of the 15 items on the self-report questionnaire, four items were bio-data questions. Four items consisted of Yes/No questions combined with six multiple choice questions and an open response follow-up question at the end. All items were followed by comment spaces where students had the chance to better elaborate their thoughts and ideas. The items used in the questionnaire were based on Shimo (2003) and adapted to measure learner responses from an assessment point of view. The questionnaire was written originally in Albanian and it was given to students during the final December class of the winter 2012 semester. All student responses to open-ended were written first in Albanian and then translated into English by the researcher.

\section{Student perceptions of assessment and traditional tests}

Let's see and analyze the data collected from the questionnaire:

First question: "What effects do tests have on your learning of the English language?" :

Table 1.

\begin{tabular}{|l|c|c|}
\hline Responses & $\mathrm{Nr}$ & $\%$ \\
\hline Tests motivate you into learning more. & 41 & $51 \%$ \\
\hline You become so nervous that you forget what you have learned. & 24 & $30 \%$ \\
\hline You are so worried about your exam that you cannot concentrate on your studies. & 15 & $19 \%$ \\
\hline
\end{tabular}

Some of the comments given by the students were:

- Tests make me feel stressed and I always receive lower grades that when the teacher interrogates me during the lesson.

- Whenever I have an English exam I always try to take notes of the teacher's instructions about the exam and I try to learn even harder.

- I love English tests! It is my most favorite subject at school.

- The exams our teacher prepares are too easy and most of the time we take good grades.

- Tests are very important because they show to our teacher and to our parents our progress in English.

As it can be seen from the above answers and comments, the students are divided into two nearly equal major groups. While one group is composed of students that are stimulated to learn more because the need to prepare for their exams, the other one includes students that feel extremely nervous and anxious before the English tests and consequently receive low grades in the end. Despite these diverse answers, it should be noted that students of this fairly young age have the tendency to consider tests and examinations as a necessary and obligatory tool for the assessment of their knowledge. They are generally positive towards any type of activity proposed by their teachers, even testing.

The second question: "What are the problems you encounter whenever you sit for an exam?

Table 2.

\begin{tabular}{|l|c|c|}
\hline Responses & $\mathrm{Nr}$ & $\%$ \\
\hline The exercise is not clear. & 10 & $12 \%$ \\
\hline
\end{tabular}




\begin{tabular}{|l|l|l|}
\hline There are words you do not understand in the test. & 34 & $42 \%$ \\
\hline The test is very difficult for you. & 36 & $45 \%$ \\
\hline
\end{tabular}

It is clear from the collected responses that the students encounter difficulties adapting to the level of the exercises in the test or in various words they are not familiar with. In spite of this, the comments received resulted very helpful into creating a better picture of the typology of the problems that students generally have to face whenever they sit for an exam. Hence, below are listed some of the most typical notes written by the students:

- Many of the exam exercises are new to us. We have never dealt with similar exercises in class but nevertheless the teacher is willing to explain these exercises to us before the test begins.

- The teacher tries to explain the words which are unknown to us but she doesn't translate each and every word.

- I sometimes do not understand what I need to do in a particular exercise. Our teacher talks in English all the time, even when she explains the exam. .

Third question: "How many times a year are you assessed (through tests or even through other assessment tools that the teacher has chosen to you for your assessment).

The responses were these:

Table 3.

\begin{tabular}{|l|c|c|}
\hline Responses & $\mathrm{Nr}$ & $\%$ \\
\hline Twice per semester & 24 & $30 \%$ \\
\hline Three times per semester & 53 & $66 \%$ \\
\hline Four times per semester & 3 & $4 \%$ \\
\hline
\end{tabular}

In the responses given, it is easy to notice an odd distribution of the respective percentages. Maybe, this happens due to the fact that not all the students are assessed with the same frequency and rhythm compared to other students. Another reason is that different teachers apply a different number of assessment tools in their classrooms. This logic is also mirrored in the below comments that the students gave:

- My teacher assesses me only during/after exams and tests, because I am not active during classes.

- I receive a lot of grades throughout the school year because she interrogates me a lot.

- $\quad$ Our teacher prepares many 20-minute long tests for only 5 or 6 students and this is how we receive most of the grades throughout the school year.

- Formal tests are scheduled twice per term and the teacher hands back the marked tests for us to show our parents.

The fourth question: "How often does the teacher explain the test articles in the test?:

Table 4.

\begin{tabular}{|l|c|c|}
\hline Responses & $\mathrm{Nr}$ & $\%$ \\
\hline Often & 69 & $86 \%$ \\
\hline Sometimes & 11 & $14 \%$ \\
\hline Rarely & 0 & $0 \%$ \\
\hline
\end{tabular}

As it can be noted, the majority of the students receive the necessary explanations for the exam questions from their teachers and for $69 \%$ of the students, this phenomenon happened frequently. This is a very positive indicator and it needs to be appreciated because the guidelines and explanations received prior and during the exam are very important and closely related to the test results. Taking into consideration the young age of the students and their respective language competence, it is mandatory for them to be given the adequate explanations by their teachers regarding the content of the exam.

The fifth question: "What do you notice about your mistakes in the test after it has been graded and marked by your teacher?"

The respective responses and percentages were as follows: 
Table 5.

\begin{tabular}{|l|c|c|c|c|}
\hline Responses & \multicolumn{2}{|c|}{ YES } & \multicolumn{2}{c|}{$\mathrm{NO}$} \\
\hline & $\mathrm{Nr}$ & $\%$ & $\mathrm{Nr}$ & $\%$ \\
\hline You have made numerous grammar mistakes. & 36 & $45 \%$ & 44 & $55 \%$ \\
\hline You have made word order mistakes. & 71 & $89 \%$ & 9 & $11 \%$ \\
\hline You have made spelling mistakes. & 76 & $95 \%$ & 4 & $5 \%$ \\
\hline
\end{tabular}

From the many comments received by the students, we are listing some of them:

- I make more mistakes in the correct spell of the words rather than in grammar, but our teacher is very interested in the grammar aspect of the exam.

- To me, grammar is very difficult and it is in grammar that I make the most mistakes.

- In English words are pronounced differently and written differently and this is why I make numerous mistakes in writing, I keep forgetting the right spelling of the words. In Albanian I find it easier because words are written as they are spoken!!!

- The word order in the English language is different from the Albanian word order and my problem is that I don't think in English but I still think in Albanian and then translate the sentence into English. This is why I make a lot of mistakes in correctly ordering the words in a sentence.

It is interesting to notice that it is the lexical errors and mistakes in word order that prevail compared to the problems that the students encounter with grammar issues. This phenomenon can be explained with the fact that the teachers pay a lot of attention during class hours to the grammar elements of the language rather than the lexical ones. What is more, the huge difference between the two respective languages, impede the students from correctly ordering the words in the sentences and even from correctly writing them.

The sixth question: "In what type of exercises do your teachers focus more when they test or assess you?

Table 6.

\begin{tabular}{|l|c|c|c|c|}
\hline Responses & \multicolumn{2}{|c|}{ YES } & \multicolumn{2}{c|}{$\mathrm{NO}$} \\
\hline & $\mathrm{Nr}$ & $\%$ & $\mathrm{Nr}$ & $\%$ \\
\hline Exercises on grammar & 80 & $100 \%$ & 0 & $0 \%$ \\
\hline Exercises on writing & 45 & $56 \%$ & 35 & $44 \%$ \\
\hline Exercises on word order & 12 & $15 \%$ & 68 & $85 \%$ \\
\hline
\end{tabular}

Even in this question it can be noted that the grammar exercises take up most of the time and space in tests and assessment. Teachers put a lot more emphasis on the application of these types of exercises compared to others. Let's look more closely at how this phenomenon is reflected in some of the comments offered by the students:

- Grammar is more important than anything else in the case of the English language and our teacher keeps reminding this to us.

- Without grammar we can not create sentences!

- I do not spend a lot of time learning new words, but I always try to learn grammar rules. Our teacher always asks us to deal with grammar exercises.

It is quite interesting to see that this focus on grammar is a direct consequence of the teachers' statements about the superior importance of this linguistic element among others. Consequently, students spend much of their time and energy just focusing on grammar exercises. It is widely accepted that grammatical issues and problems should be highlighted and analyzed carefully by teachers but this does not mean that they should prevail against other linguistic issues. A thorough orientation to the Grammar-Translation method is proved to have brought deep problems in the real future communication of the students in a foreign environment and setting. It is necessary that teachers start by reflecting to the students the change of this course and direct them to other linguistic exercises and equate the role and importance of each of them in the EFL classroom.

While the seventh question was focused more on the skill elements: "In what skills in the use of English do your teachers focus more when they test or assess you? 
Table 7.

\begin{tabular}{|l|c|c|}
\hline Responses & $\mathrm{Nr}$ & $\%$ \\
\hline In your speaking skill & 26 & $32 \%$ \\
\hline In your writing skill & 47 & $59 \%$ \\
\hline In your reading skill & 7 & $9 \%$ \\
\hline In your listening skill & 0 & $0 \%$ \\
\hline
\end{tabular}

Once again we see a disproportionate share of the weight that the students' language skills have in the assessment process. On one hand, there is an overload on the assessment of the writing ability as this is a skill which can not be overlooked during classes. On the other hand, the speaking skill is less stressed and even less importance is given to the reading skill. It is interesting to notice that no student responded positively about the listening skill. This clearly shows a total lack of the application of listening activities, at least in terms of assessment.

It is worth mentioning that the term 'listening' in the questionnaire refers to the listening exercises and activities that are part of the student's textbook the students used which is accompanied by audio material that would offer students a variety of voices, pronunciation, dialects and intonations. Naturally, students practice listening skills by listening to the teacher and to each other but these listening activities are not always correct and this is the reason why in this study we take into analysis the intensive listening skill through audio materials. This aspect was made known to the students and teachers together at the very beginning of the research so that they were as clear as possible when analyzing and giving their answers. follows:

The eighth question: "When do your teachers give you feedback on your assessment?" The responses were as

Table 8.

\begin{tabular}{|l|c|c|}
\hline Responses & $\mathrm{Nr}$ & $\%$ \\
\hline Only after exams and tests & 63 & $79 \%$ \\
\hline Whenever you prepare homework, essays, presentations etc. & 11 & $14 \%$ \\
\hline Whenever you are unprepared & 6 & $7 \%$ \\
\hline
\end{tabular}

As it can be seen from the results, it seems clear that the exams are the key elements that students believe that teachers use to assess. Perhaps it is also because this is a tangible and visible assessment, which is declared and made known to the students in writing whenever they are given back their marked exams. Accordingly, these are the assessments that students recognize as such. This mode of thinking is found reflected even in their comments:

- My English teacher puts me a grade only when we do exams.

- Whenever we prepare homework or class work, we discuss them in the classroom but we are not given a grade for this.

- We receive grades when we do an exam but we also receive a low grade when we are unprepared.

The ninth and the tenth questions:

Question 9 "Does your teacher give you the possibility to assess yourself?

Question 10 "Have you ever assessed your classmates?"

These were the responses:

Table 9.

\begin{tabular}{|l|c|c|c|c|}
\hline Responses & \multicolumn{2}{|c|}{ YES } & \multicolumn{2}{c|}{ NO } \\
\hline & $\mathrm{Nr}$ & $\%$ & $\mathrm{Nr}$ & $\%$ \\
\hline Does your teacher give you the possibility to assess yourself? & 0 & $0 \%$ & 80 & $100 \%$ \\
\hline Have you ever assessed your classmates? & 2 & $2 \%$ & 79 & $98 \%$ \\
\hline
\end{tabular}

Students generally responded negatively on the provision of an opportunity to assess each other. Furthermore, these data shows that the 80 students participating in this study admitted that they were never given the opportunity to assess themselves. Both these figures tell us a lot about the role of teachers and students in the assessment process in particular, and perhaps even on that of teaching in general. This is a problematic element especially if we take into 
consideration the role that self-esteem plays in today's pedagogy of teaching foreign languages. The mentality of teachers who view assessment as a right that belongs only to them and that can not be exercised though informally by students is deeply rooted and it will naturally take time, will and hard work to get changed. Comments of students, some of which are presented below, materialized our assumptions on these issues:

Comments on question 9.

- We cannot assess ourselves; the teacher can do this because she knows more than we do.

- We are still too young to assess ourselves.

- I still do not enough English to correct myself or my mistakes

- It is the teacher's task to assess us. Our task is to learn.

For question number 10 the comments received were:

- I am very curious to see what evaluation my friend has received by the teacher, but I am not able to assess him or her.

- Once, the teacher told us to take our friend's homework and correct it. After we finished with our corrections, together with the teacher we went through all the exercises so as to see if we had made any mistakes in our correction. I really liked this experience because I felt as a teacher.

- We are not capable of assessing one another, because some students are good at English and some others are not.

- We tried this once in class, but my friend's handwriting was so bad that I couldn't understand it.

From these comments and from many other similar ones, it is clear that peer assessment and self-assessment are two skills that have not received due attention in the teaching process. Still today, the teacher plays a central role in class and students are those who follow the guidelines and assessment given by the teacher only.

The last question of our questionnaire required from the students to think critically about assessment in general and the followed procedures in particular. Through this questionnaire, we offered to the students the opportunity that for just a brief moment they could be put in the role of their assessors and think about possible improvements to the process. Responses have been varied and sometimes surprising. Let us see some of them as follows:

- $\quad$ There should be more exams during the school terms.

- We need to be assessed more and this assessment should be shown to us.

- There are many cases when our teachers do not tell us what grades we have received, and such a phenomenon worries our parents who are confronted with a lower grade than expected at the end of the school year.

- It would be great if our teachers explained to us the particular grade we might have received in an exam and after that give to us the right solutions to the problems.

- $\quad$ Our teacher does not usually correct our homework and I spend a lot of time at home preparing them. I would like to be given a grade even about my homework.

- I would love to be given the opportunity to assess myself and my friends because I believe that in this way we will be able to better understand our mistakes in English.

It is evident from these responses that students are generally capable of critically viewing the learning process and they draw their own conclusions about possible improvements in this area.

\section{Conclusion}

Learners in this pilot study agreed that tests and assessments made them learn more as they needed to achieve good results and thus they were encouraged to review previously acquired knowledge in order to be ready for the next assessment. However, there were some of them for whom the aspect of testing and assessment constituted a difficult moment. Before, during and after the process, they felt under psychological pressure.

The study clearly showed that grammar and writing exercises prevailed in comparison with other types of testing articles. Few were those students who mentioned exercises in reading and speaking while students did not mention any of the listening exercises. Most of the respondents had full confidence that grammar exercises were the most important ones and therefore these should be best learned as the teachers put a lot of emphasis on these types of exercises. The message from teachers to students was: without grammar one can not learn a foreign language.

Many of the respondents replied that many of the mistakes they made related to grammar elements. Many of the students stated that they often failed to correctly write many words in the English language in their writing. They expressed that it was difficult to memorize the exact spelling of English words, because it required that they not only 
learn the correct pronunciation and meaning of the word, but also the way it was correctly written.

Learners in this pilot study agreed that self and peer assessment offer an assessment not available through traditional testing: learners can have their learning processes assessed and are provided with the chance to reflect about their own work. Self and peer assessment also can provide learners with ample feedback from peer and teachers, increasing cooperative learning and motivation.

It is quite interesting to note that there are many students who require more tests and more assessment activities by their teachers before they could set them a grade. It is the learners themselves that require to be evaluated not only through tests, but also through exercises in reading, writing and speaking. We regret to see that the students' responses in relation to listening activities were completely missing.

\section{References}

Amy Hamilton. (2010). Collaborative learning \& self-and peer assessment. EDES9632. Normal Capital University, Beijing. Brown, H.D. 2007 Teaching by Principles "An interactive Approach to Language Pedagogy" Pearson, Longman

Cohen, A. (1994). Assessing language abilitity in the classroom (2nd ed.) Boston

Cohen, L. Manion, L. and Morrison, K. (2000) Research Methods in Education (5th Edition). London: Routledge/Falmer.

Coombe, C., Folse, K. \& Hubley, N (2007). A practical guide to assessing English language learners. Ann Arbor, Ml: University of Michigan Press

Hamp-Lyons, L., \& Condon, W. (2000). Assessing the portfolio: Principles for practice, theory, and research. Cresskill: Hampton Press.

Shimo, E. (2003). Learners' perceptions of portfolio assessment and autonomous learning. In A. Barfield \& M. Nix (Eds.), Teacher and learner autonomy in Japan, Vol. 1: Autonomy You Ask! (pp. 175-186). Tokyo: Japan Association for Language Teaching Learner Development Special Interest Group. 